\title{
Synthesis of mono layer graphene oxide from sonicated graphite flakes and their Hall effect measurements
}

\author{
MUHAMmad SIYAR $^{1 *}$, Asghari MAQSOOD $^{2}$, SADAF BASHIR KHAN $^{1}$ \\ ${ }^{1}$ Thermal Transport Laboratory, Department of Material Engineering, School of Chemical and Material Engineering, \\ National University of Sciences and Technology, Islamabad-44000, Sector H-12, Pakistan \\ 2 Department of Physics, Air University, E-9 PAF Complex, Islamabad, Pakistan
}

\begin{abstract}
Graphene, a single atom thick sheet is considered a key candidate for the future nanotechnology, due to its unique extraordinary properties. Researchers are trying to synthesize bulk graphene via chemical route from graphene oxide precursor. In the present work, we investigated a safe and efficient way of monolayer graphene oxide synthesis. To get a high degree of oxidation, we sonicated the graphite flakes before oxidation. X-ray diffraction (XRD) and Fourier transform infrared spectroscopy (FTIR) results confirmed graphene oxide formation and high degree of oxidation. Raman spectroscopy and atomic force microscopy (AFM) results revealed a monolayer of graphene oxide (GO) flakes. The sheet like morphology of the GO flakes was further confirmed by scanning electron microscopy (SEM). The Hall effect measurements were performed on the GO film on a silica substrate to investigate its electrical properties. The results obtained, revealed that the GO film is perfectly insulating, having electrical resistivity up to $8.4 \times 10^{8}(\Omega \cdot \mathrm{cm})$ at room temperature.
\end{abstract}

Keywords: GO (grapheme oxide); monolayer; sonication; electrical resistivity

(C) Wroclaw University of Technology.

\section{Introduction}

Graphene, a monolayer planar sheet of densely packed carbon atoms in a honey-comb like crystal structure, has brought a radical revolution in electronics and nanoscience due to its outstanding electrical, mechanical, ballistic transport properties, chemical inertness, and transparent nature [1-6].

Scientists are trying to get single layer graphene sheets on an industrial scale. But there are some potential barriers to overcome before we will be able to get the full range of advantages from this magical material. The main issue is to commercialize it industrially as a high quality product. So many efforts have been done for this purpose and various techniques have been developed, such as the bottom-up approach, chemical vapor deposition (CVD), epitaxial growth on SiC substrate, arc discharge and chemical route [7-10]. In the topdown approach, chemical exfoliation and mechan-

*E-mail: engrsiyar.uet@gmail.com ical exfoliation via adhesive scotch tape processes has been reported $[11,12]$.

Chemical route is one of the possible ways to get graphene in bulk quantity. Chemical route for graphene synthesis is the most appropriate way for composites applications. For the first time Brodie [13] studied the chemical exfoliation of graphite in the mid of $19^{\text {th }}$ century through the addition of nitric acid to a mixture of potassium chlorate and graphite. Then, Staudenmaier [14] continued the efforts and got reasonable results. In 1958 Hummer [15] used potassium permanganate and sulphuric acid to oxidize graphite into graphene oxide successfully.

Various efforts have been done so far to apply graphene for different applications, including fuel cells, lithium ion batteries and biomedical applications [16-18].

Graphene oxide is obtained by chemical exfoliation which is further used as a precursor for various composites, through different routes, such as sol gel, co-precipitation and hydrothermal synthesis [19-21]. To date main focus has been made to 
get single or bilayer GO sheets and high degree of oxidation to get improved properties of composites. Sun and Fugetsu [22] recently demonstrated pre-sonication techniques coupled with Hummer route [15] to get high oxidation of graphite into a large area of GO sheets. But in this method the authors used commercial expanded graphite flakes, which may not be feasible on industrial scale production. The electrical properties of GO should be explored, for targeted application in various areas. As far as single graphene sheet is concerned, its conductivity is intensively studied theoretically [23] and experimentally [24-26]. Recently, some work has been done to study the conductivity of GO and its derivatives [27, 28].

In this work, we prepared graphene oxide by two step approach. Graphite flakes were sonicated in acetic acid before oxidation for pre-expansion, and then the mixture of two acids was used for good acidification before oxidation. We revealed after analyzing the data obtained from different characterization techniques that most of the flakes of GO formed a single layer. Also the XRD data showed the high degree of oxidation for this novel method. The Hall effect measurements provided the evidence about the insulating nature of GO.

\section{Experimental}

\subsection{Materials}

Sulphuric acid $\left(\mathrm{H}_{2} \mathrm{SO}_{4}\right)(98 \%)$, hydrochloric acid $(\mathrm{HCl})$, acetic acid $(100 \%)$ all of analytical grades and graphite flakes $(20 \mu \mathrm{m})$ were provided by Sigma Aldrich. Nitric acid was purchased from Fisher Scientific and potassium permanganate from Sharlau Chemicals. All the chemicals were used as received.

\subsection{Synthesis of GO}

$2 \mathrm{~g}$ of graphite flakes were put into a $500 \mathrm{ml}$ beaker and $20 \mathrm{ml}$ of acetic acid was added. Sonication was continued for 5 hours at room temperature and then the stuff was washed with deionized water for five times to get neutral $\mathrm{pH}$. Sonicated graphite platelets were dried for 10 hours at $80{ }^{\circ} \mathrm{C}$.
Then, these sonicated graphite platelets were taken into a flask, and a mixture of $\mathrm{H}_{2} \mathrm{SO}_{4}(30 \mathrm{ml})$ and nitric acid $(10 \mathrm{ml})$, in a ratio of $(3: 1)$, was added and slowly stirred for 1 hour. Potassium permanganate $\left(\mathrm{KMnO}_{4}\right)$ of mass $6 \mathrm{~g}$ was added to the mixture slowly and vigorously stirred for 1 hour. When the yellow vapors ceased, the mixture was diluted with $100 \mathrm{ml}$ warm water and left for 3 days stirring. The yellowish paste obtained was diluted with $200 \mathrm{ml}$ water containing $2 \mathrm{ml}$ hydrogen peroxide $\left(\mathrm{H}_{2} \mathrm{O}_{2}\right)$ to stop the reaction. After decantation for 12 hours the cake obtained was washed for two times with $\mathrm{HCl}$ and then thoroughly with distilled water until $\mathrm{pH}=7$ was achieved. The dark brown paste was dried in a vacuum oven for 24 hours to get solid GO.

\section{Characterizations}

The XRD pattern of the GO was taken with a STOE Theta/Theta Diffractometer, using $\mathrm{Cu}-\mathrm{K} \alpha$ source in the range of $2 \theta$ from 8 to 80 degrees. The GO sheet thickness was measured in a tapping mode with a JEOL (JSPM-5200) scanning probe microscope and the morphology was further confirmed by scanning electron microscope (JSM_6490A). Chemistry of the GO sheets was studied by Fourier transform infrared spectroscopy (Nicolet 6700).

Hall effect measurements were performed using Ecopia HMS-5000 system. The GO film was carefully deposited by a simple drop casting method so as to obtain a smooth film. The film formed was nearly transparent. The film thickness was measured with a $3 \mathrm{D}$ optical profilometer for electrical measurements.

\section{Results and discussion}

\subsection{Oxidation of graphite}

In Fig. 1, XRD spectra are shown for both the starting material (graphite) and GO. The two peaks which can be seen in the pattern, the principal peak at 26 degrees and a minor peak at 54 degrees in the spectrum (A), confirm graphite structure of the starting material [29]. The sharp peak at 10 degrees 
in spectrum (B) corresponds to (002) plane of interlayer distance of $6.7 \AA$. The high intensity single peak confirms successful oxidation of graphite into GO [30-32].

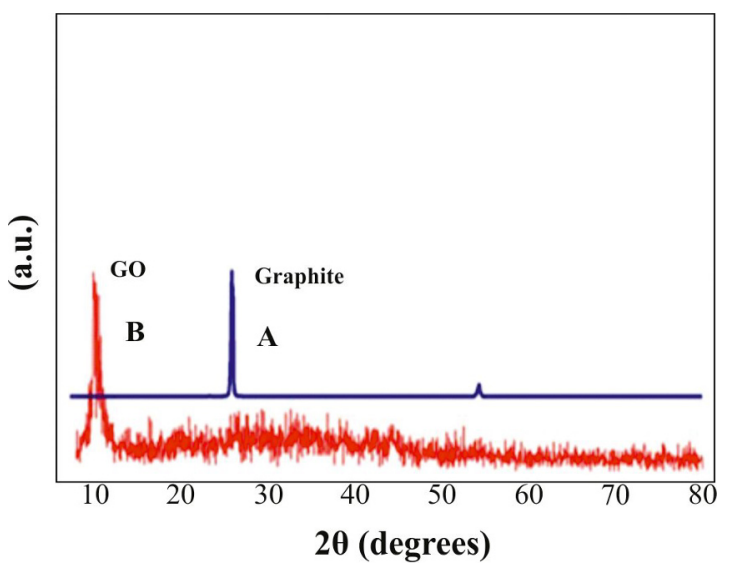

Fig. 1. XRD spectrum of graphite (A) and GO (B).

\subsection{Functional group analysis of GO}

The FTIR spectrum obtained in frequency range from $1000 \mathrm{~cm}^{-1}$ to $4000 \mathrm{~cm}^{-1}$ is shown in Fig. 2. The broad peak beyond $3000 \mathrm{~cm}^{-1}$ can be attributed to $\mathrm{O}-\mathrm{H}$ stretching vibration, the small peak at $1740 \mathrm{~cm}^{-1}$ represents $\mathrm{C}=\mathrm{O}$ group, the $\mathrm{C}-\mathrm{H}$ stretching appears at two peaks corresponding to $2851 \mathrm{~cm}^{-1}$ and $2924 \mathrm{~cm}^{-1}$. The peak at $1389 \mathrm{~cm}^{-1}$ refers to $\mathrm{C}-\mathrm{N}$ stretching, while the $1034 \mathrm{~cm}^{-1}$ peak can be attributed to $\mathrm{C}-\mathrm{N}$ stretching. All these peaks are characteristic of GO [33-36].

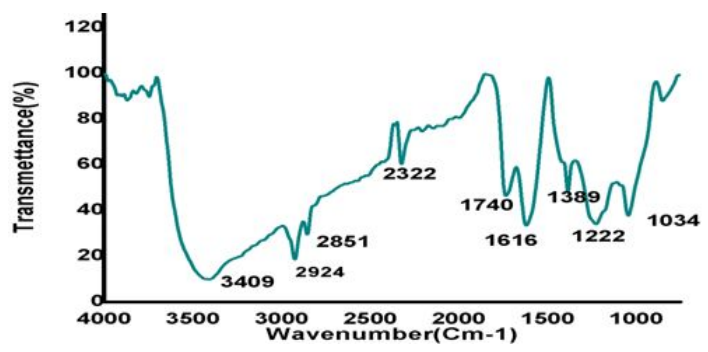

Fig. 2. FTIR spectra of as prepared GO.

\subsection{Raman spectroscopic analysis}

Raman analysis was performed using Lab RAM $800 \mathrm{HR}$ (made by HORIBA) in the range of
$1100 \mathrm{~cm}^{-1}$ to $2800 \mathrm{~cm}^{-1}$ with a laser of excitation energy $1.96 \mathrm{eV}$ and 1 to $2 \mathrm{~cm}^{-1}$ spectral resolution. The results are shown in Fig. 3.

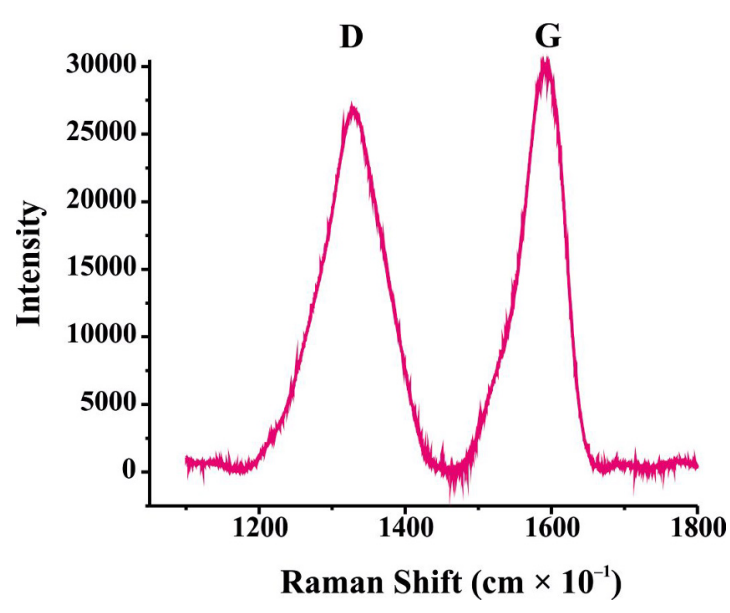

Fig. 3. Raman spectra of GO sample on silica substrate.

The spectrum reveals two pronounced features of GO at $1330 \mathrm{~cm}^{-1}$ and $1591 \mathrm{~cm}^{-1}$, which are referred to $\mathrm{D}$ and $\mathrm{G}$ bands, respectively. The $\mathrm{D}$ band is due to the structural imperfections caused by the hankering of $\mathrm{OH}$ and epoxy groups on the basal plane of carbon. The $\mathrm{G}$ band at $1591 \mathrm{~cm}^{-1}$ is an evidence of the $\mathrm{sp}^{3}$ and $\mathrm{sp}^{2}$ hybridization, due to distortion in the crystal structure of the carbon atoms, resulting from oxidation. Relatively short FWHM and nearly the same intensity of both the peaks, shown in Table 1, reveal that GO flakes obtained are mostly monolayer as reported previously [37-39].

Table 1. Peak analysis data of Raman spectra for GO on silica substrate.

\begin{tabular}{ccc}
\hline GO & D & G \\
\hline \hline Peak position & $1330 \mathrm{~cm}^{-1}$ & $1591 \mathrm{~cm}^{-1}$ \\
FWHM & $98 \mathrm{~cm}^{-1}$ & $67 \mathrm{~cm}^{-1}$ \\
Height & $27117(\mathrm{au})$ & $30324(\mathrm{au})$ \\
\hline
\end{tabular}

\subsection{Average sheet thickness and morphology}

Fig. 4 shows an AFM topographic image of GO. The color contrast and profile height show that all 
Table 2. Hall Effect Measurement data for GO sheets on a glass substrate.

\begin{tabular}{ccccccc}
\hline $\begin{array}{c}\text { Temp. } \\
\mathbf{K}\end{array}$ & $\begin{array}{c}\text { Current I } \\
(\mathbf{A})\end{array}$ & $\begin{array}{c}\text { Bulk concentration } \\
\left(\mathbf{c m}^{\mathbf{3}}\right)\end{array}$ & $\begin{array}{c}\text { Resistivity } \\
(\mathbf{O h m} \cdot \mathbf{c m})\end{array}$ & $\begin{array}{c}\text { Conductivity } \\
\left(\mathbf{S} \bullet \mathbf{c m}^{\mathbf{- 1}}\right)\end{array}$ & $\begin{array}{c}\text { Mobility } \\
\left(\mathbf{c m}^{\mathbf{2}} \cdot \mathbf{V}^{-\mathbf{1}} \cdot \mathbf{s}^{\mathbf{- 1}}\right)\end{array}$ & $\begin{array}{c}\text { Avg Hall coefficient. } \\
\left(\mathbf{c m}^{\mathbf{3}} \mathbf{C}^{-\mathbf{1}}\right)\end{array}$ \\
\hline \hline 300 & $1.00 \mathrm{E}-11$ & $5.27 \mathrm{E}+08$ & $8.37 \mathrm{E}+07$ & $1.20 \mathrm{E}-08$ & $1.42 \mathrm{E}+02$ & $-1.19 \mathrm{E}+10$ \\
\hline
\end{tabular}

the GO flakes are of about the same thickness in the range of about 0.6 to $0.7 \mathrm{~nm}$. These observations are consistent with the previous reports [40]. The morphology of GO sheets is further confirmed by SEM images. It can be seen in Fig. 5 that the GO sheets obtained are individually dispersed and have an average length of $2 \mu \mathrm{m}$.

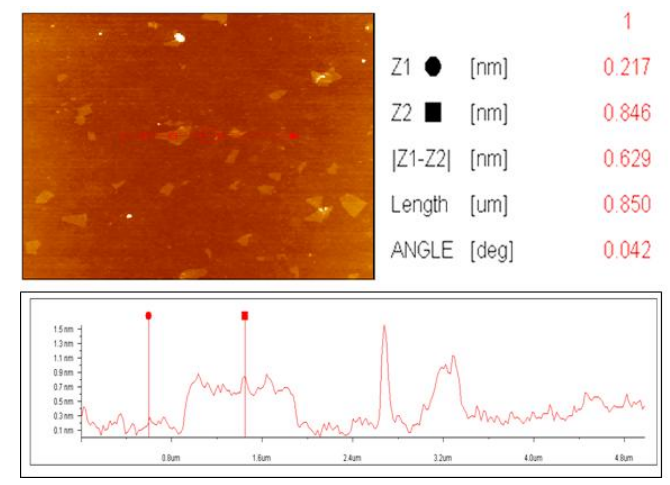

Fig. 4. AFM tapping mode, topographic image of GO on silica substrate.

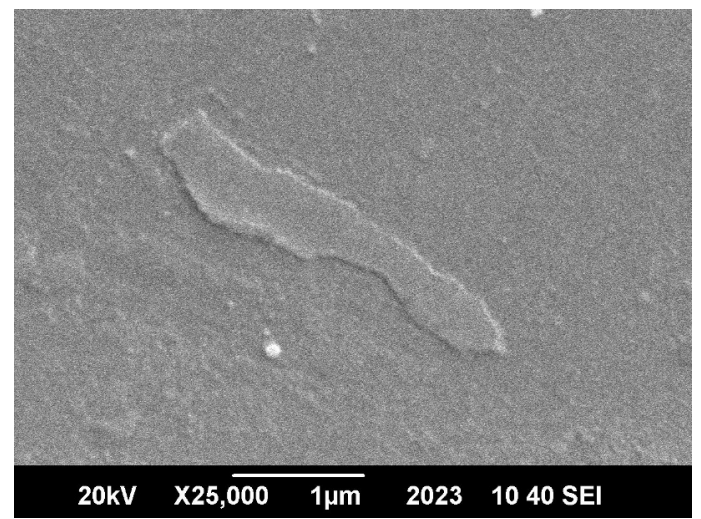

Fig. 5. Scanning electron microscope image of GO single flake.

\subsection{Electrical properties}

According to Hall effect measurement data the GO film has the resistivity value up to
$8.37 \times 10^{7} \Omega \cdot \mathrm{cm}$ at room temperature, the bulk concentration of GO film is $5.27 \times 10^{8} \mathrm{~cm}^{3}$, and a very low conductivity $1.20 \times 10^{-8} \mathrm{Scm}^{-1}$. So, these data reveal that the GO film is an insulator with strong p-type conductivity at room temperature. Our results are consistent with the previous studies [41, 42].

\section{Conclusions}

In the present work, we have reported a new and safe synthesis route for GO formation. The XRD results confirmed the high degree of oxidation and Raman analysis revealed that most of the GO sheets formed a monolayer. Moreover, we performed the Hall measurements and found that the GO film is of p-type conductivity and has insulator properties.

\section{Acknowledgements}

The authors acknowledge PSF (Pakistan Science Foundation)/project 147 for providing funds.

\section{References}

[1] ChOI W., Won J., ,Graphene: Synthesis and Applications, Lee CRC Press, New York, 2011.

[2] Go C., Nava M., Scolari M., Mews A., Burghard M., Kern K., Nano Lett., 7 (2007), 3499.

[3] FRANK I.W., TANENBAUM D.M., VAN DER ZANDE A.M., MCEuEN P.L., J. Vac. Sci. Technol. B, 25 (2007), 2558.

[4] Du X., Skachko I., Barker A., Andrei E. Y., Nat. Nanotechnol., 3 (2008), 491.

[5] CAi J., RuffieUX P., JAAFAR R., BIERI M., BRAUN T., Blankenburg S., Muoth M., Seitsonen A.P., Saleh M., Feng X., Müllen K., Fasel R., Nat. Commun., 466 (2010), 470.

[6] Yao J., Lin J., Dai Y., Ruan G., Yan Z., Li L., Zhong L., NATElson D., Tour J.M., Nat. Commun., 3 (2012), 1101.

[7] Mattevi C., Kim H., Chhowalla M., J. Mater. Chem., 21 (2011), 3324.

[8] Emtsev K.V., Bostwick A., Horn K., Nat. Mater., 8 (2009), 203. 
[9] Subrahmanyam K.S., Panchakarla L.S., Govindaraj A., Rao C.N., J. Phys. Chem. C, 113 (2009), 4257.

[10] Gilje S., Han S., Wang M., Wang K.L., KaneR R.B., Nano Lett., 7 (2007), 3394.

[11] Meng L.Y., Park S.J., B. Korean. Chem. Soc., 33 (2012), 209.

[12] Novoselov K.S., GeIM A.K., Morozov S.V., JiAng D., Zhang Y., Dubonos S.V., Grigorieva I.V., FIRSOV A.A., Science, 306 (2004), 666.

[13] Brodie B.C., Ann. Chim. Phys., 59 (1860), 466.

[14] Staudenmaier L., Ber. Dtsch. Chem. Ges., 31 (1898), 1481.

[15] Hummers W.S., Offeman R.E., J. Am. Chem. Soc., 80 (1958), 1339.

[16] Xiao L., Damien J., Luo J., Jang H.-D., Huang J., He Z., J. Power Sources, 208 (2012), 187.

[17] Elzatahry A.A., Abdullah A.M., Din T.A., AlEniz A.M.I., MaArouf A.A., Galal A., Hassan H.K., El-Ads E.H., Al-Theyab S.S., Al-Ghamdi A.A., Int. J. Electrochem. Sc., 7 (2012), 3115.

[18] BIN M.H., XIN S.W., XIN T.Z., FeI S.D., BIN Y.X., BIN L., Ji X.Q., Chinese. Sci. Bull., 57 (2012), 3051.

[19] Zhang X.Y., Li H.P., CUi X.L., Lin Y., J. Mater. Chem., 20 (2010), 2801.

[20] Behera S.K., Chem. Commun., 47 (2011), 10371.

[21] Shen C., Zheng M., Xue L., Li N., LÜ H., Zhang S., CAO J., J. Chem., 29 (2011), 719.

[22] Sun L., Fugetsu B., Mater. Lett.,109 (2013), 207.

[23] Castro A.H., Guinea F., Peres N.M., Novoselov K.S., Geim A.K., Rev. Mod. Phys., 81 (2009), 109.

[24] Li Z.Q., Lu C.J., Xia Z.P., Zhou Y., Luo Z., Carbon, 45 (2007), 1686.

[25] Geim A.K., Novoselov K.S., Nat. Mater., 6 (2007), 183.

[26] Zhan Y., Tan Y.W., Stormer H.L., Kim P., Nat. Commun., 438 (2005), 201.

[27] Novoselev K.S. et al., Science, 315 (2007), 1379.
[28] Li Z.J., Yang B.C., Zhang S.R., ZhaO C.M., Appl. Surf. Sci., 258 (2012), 3726.

[29] Venugopal G., Krishnamoorthy K., Mohan V., Kim S.J., Mater. Chem. Phys., 132 (2012), 29.

[30] Marcano D.C., Kosynkin D.V., Berlin J.M., Sinitskit A., Sun Z., Slesarev A., Alemany L.B., LU W., Tour J.M., Nano, 4 (2010), 4806.

[31] Nguyen V.H., Kim B.K., Jo Y.L., Shim J.J., J. Supercrit. Fluid., 72 (2012), 28.

[32] Wang H., Wang L., Qu C., Su Y., Yu S., Zheng W., LIU Y., J. Solid State Chem., 184 (2011), 881.

[33] Stankovich S., Dikin D.A., PIner R.D., KohlhaAs K.A., Kleinhammes A., JiA Y., Wu Y., Nguyen S.T ., Ruoff R.S., Carbon, 45 (2007), 1558.

[34] XU Z., Gao C., Nat. Commun., 2 (2011), 1.

[35] Stankovich S., Piner R.D., NGUYen S.T., RuOFF R.S., Carbon, 44 (2006), 3342.

[36] Jiang Y., Zhang Q., Li F., NiU L., Sensor. Actuat. B-Chem., 161 (2012), 728.

[37] Hilder M., Winther-Jensen O., WintherJensen B., Macfarlane D.R., Phys. Chem. Chem. Phys., 14 (2012), 14034.

[38] Compton O.C., An Z., Putz K.W., Hong B.J., Hauser B.G., Brinson L.C., NGuyen S.T., Carbon, 50 (2012), 3399.

[39] Pham V.H., CuOng T.V., Hur S.H., OH E., KIm E.J., Shin E.W., Chung J.S., J. Mater. Chem., 21 (2010), 3371.

[40] Huang X., Zhi C., Jiang P., Golberg D., Bando Y., TANAKA T., Nanotechnology, 23 (2012).

[41] Kim K.S., Zhao Y., Jang H., LeE S.Y., Kim J.M., KIM K.S., AhN J.H., Kim P., CHOI J.Y., Hong B.H., Nature, 457 (2009) 706.

[42] Freitag M., Nat. Nanotechnol., 3 (2008) 455.

Received 2014-01-15 Accepted 2014-03-19 